\title{
Effect of repair parameters on composite plates under low velocity impact
}

\author{
Mustafa Albayrak ${ }^{1^{*}}$, Mustafa Gür², Mete Onur Kaman²
}

' Department of Machine and Metal Technologies, Malatya Organized Industrial Zone Vocational School, Inonu University, 44900, Malatya, Turkey, 2 Department of Mechanical Engineering, Engineering Faculty, Firat University, 23119 Elazig, Turkey

Orcid: M. Albayrak (0000-0002-29I3-6652), M. Gür(0000-0002-476I-02I5), M.O. Kaman (0000-0003-0I78-6079)

\begin{abstract}
In this study, the impact behavior of patch-repaired layered composite plates was numerically investigated under low velocity impact loads. For this purpose, composite plates designed in different geometric combinations were repaired with patches using various adhesives. Impact behavior of these composites investigated by dropping the strikers with different velocities on the repaired composite plate. The laminated composite was used as the sheet and patch material, and the orientation angles were set as $\left[0^{\circ} / 45^{\circ} / 45^{\circ} / 0^{\circ}\right]$ for the sheet and $\left[0^{\circ} / 45^{\circ}\right]$ for the patch. ANSYS-Ls-Dyna finite element packet program was used for threedimensional modelling and solution. It was determined that the hexagonal patch type performs better than other patch geometries.
\end{abstract}

Keywords: Fiber reinforced composites, patch repair, low velocity impact, finite element method.

\section{Introduction}

In the light of technological developments, innovations about the design, production and repair ability of materials have emerged and various researches are carried out on their applicability. Composite materials, which are obtained by combining more than one material at a macro level, are one of these areas. Composite materials are highly preferred in machinery and building systems thanks to their ability to be produced in accordance with the intended use to contain the features of the components that make it up and to have higher strength and performance. With the development of production techniques, a significant part of the elements that constitute the machine and building system can be produced from composite materials.

Fiber reinforced composites are manufactured in thin section, i.e plate form, due to their high mechanical properties. Plates are exposed to impacts and stresses depending on where they are used, and as a result, different stresses occur. These stresses can damage the plates and prevent them from performing their essential function. Composites are mostly orthotropic materials that exhibit elastic behavior. Especially fiber reinforced composites exhibit brittle fracture behavior and damage occurs due to fiber breakage resulting from impact. These fractures also cause the start and spread of the damage on the surfaces outside the impact contact area, and sometimes even invisible delamination (separation between layers) dam- age. The effects of external impacts should be understood from all such damages and necessary precautions should be taken during the designing process. In addition, it is important to carry out studies to increase impact resistance during manufacturing or production phases.

There are various experimental and numerical studies on the behavior of composite materials under low velocity impact load; Cheng et al. [1] performed experimental and numerical impact tests on carbon fiber patch-repaired composites at different angles. They evaluated the effects of parameters such as patch angle and adhesive thickness on impact strength and damage mechanism. Ivanez et al. [2] examined the effect of impact locations on impact strength by performing impact tests on patch centers and edges of double-patch repaired carbon / epoxy composites. Tie et al. [3] made an optimization study on different patch designs to maximize the impact strength of double-patch repaired carbon fiber laminates. With this optimization, they established the most appropriate values of parameters such as radius, angle and thickness of the patch and numerically determined their effects on impact strength. Kashfuddoja and Ramji [4] numerically performed tensile tests by modeling carbon fiber reinforced polymer composites with double-patch in different geometric shapes. They compared the stress concentration factor and the peel stress in the adhesive for different patch geometries, keeping the patch volume constant. After performing impact tests at different energy levels 
on glass fiber composite tubes wrapped with the filament winding method, Kara et al. [5] repaired the damaged tubes with composite patches with different layer numbers. They examined the effect of the patches on burst pressure by subjecting the repaired tubes to monotonic internal pressure tests. Andrew et al. [6] investigated the effects of the repair by performing low velocity impact tests on glass / epoxy composite patch-repaired samples that they produced and hardened in a compression molding machine by using the hand lay-up method. Coelho et al. [7] performed single and double-patch repairs on glass fiber composites using the overlap patch technique. They then subjected it to multiple impacts until full puncture occurred in order to evaluate the impact fatigue strength. Tie et al. [8] repaired carbon fiber reinforced composites with single-patch of different geometries and sizes. They examined the effect of patch parameters on delamination surface area and impact absorption energy. Choi [9] investigated the effect of sample geometry on impact energy by performing numerically low velocity impact tests on cylindrical composite plates and shells with nonlinear geometries. Hu et al. [10] investigated the effect of kevlar fiber on impact strength by performing low velocity impact tests on carbon fiber reinforced polymer composites hardened with short kevlar fibers. Zhang et al. [11] conducted low velocity impact tests on steel-glass thermoplastic hybrid plates produced by direct injection molding process and examined the impact responses of the plates such as impact absorption energy, maximum load and damage area. Liu et al. [12] compared the impact strengths of unidirectional-woven hybrid composites and pure unidirectional carbon fiber reinforced composites at different energy levels under the same boundary conditions. Liu et al. [13] numerically and experimentally studied the impact behavior of carbon fiber flat composite plates under low velocity impact effect. Puck, Hashin and Chan-Chang have studied the intralaminar damage of composites by defining the damage criteria numerically. They evaluated the effect of these criteria on the dynamic progressive failure properties of composites. Zhang et al. [14] presented a finite element model based on continuum damage mechanisms to examine the dynamic mechanical response and damage development of cross-ply composite under different impact energies. They have applied the Hashin criterion and a gradual degradation scheme to predict the intralaminar damage initiation and evolution. They studied the damage evolution of matrix cracking and interface delamination. Bunea et al. [15] investigated the effect of the matrix properties of fiber reinforced and epoxy matrix filled hybrid composites, the number of carbon and aramid layers and the layer alignment orientation on the impact behavior under low velocity impact. As a result of the low velocity impact test, they analyzed the damage areas with visual inspection and tomographic images. In order to evaluate the mechanical behavior of multilayer carbon nanotube, flax-carbon fiber composites and flax-glass fiber hybrid composites developed as nanophiles. Ismail et al. [16] subjected them to impact tests under impact energies ranging from $5 \mathrm{~J}$ to $20 \mathrm{~J}$. Menna et al. [17] performed low velocity impact tests at numerically different energy levels on glass-epoxy layers of two different thicknesses. They defined the orthotropic failure criterion to model the damage in the layers, and the stress-based contact failure to model the delamination mechanism between plies. As a result, they analyzed the impact strength and failure behavior by drawing the reaction force graphs depending on the time and the displacement. Liu et al. [18] performed experimental and numerically low velocity impact tests on sandwich structures with carbon fiber reinforced polymer and aluminum alloy corrugated cores by means of strikers with different geometries. They investigated the impact of striker's geometries on the impact behavior of these sandwich structures.

When the literature on this subject is examined, it is seen that parameters such as adhesive thickness [1], patch angle [1], impact position [2] and patch geometry [4] have an effect on the impact strength of composites. Contrary to experimental studies [4] in which impact was applied to the center of the patch in composites repaired using adhesive, a numerical approach was introduced in this study. However, unlike the studies in which the impact of the impact applied around the patch was investigated numerically [8], the effect of the impact behavior applied to the patch center was investigated in this study. In the three-dimensional numerical model created for the solution, patched composite material was used, which was repaired using ANSYS Ls-Dyna software. The effects of the repair parameters on the repaired composite material were examined and the results obtained for the variation of the reaction force were presented in graphics.

\section{Material and Method}

\section{I. Problem Definition}

In the study, the composite plate with a hole has different geometries in the middle was repaired with a composite patch with different geometries and dimensions (Figure 1). Under low velocity impact, the effects of the impact behavior of plate hole size and shape, adhesive type and thickness, patch size and type on composite plate were investigated within different boundary conditions. In addition, the analyzes were repeated for the strikers of various speeds.

As a result of the study, contact force, displacement, tensile and compressive stresses were obtained depending on time. Layered composite plate was four layer and its orientation angles were: $\left[0^{\circ} / 45^{\circ} / 45^{\circ} / 0^{\circ}\right]$. Plate sizes were set as $180 \times 180 \mathrm{~mm}^{2}$ and each layer thickness was set as $0.5 \mathrm{~mm}$. The plate with a circular hole in the middle has been modelled for 30, 40, 45 and $50 \mathrm{~mm}$ diameters. In addition, solutions were made for square $\left(40 \times 40 \mathrm{~mm}^{2}\right)$ and 
hexagonal (edge length, 20mm) holes. Mechanical properties of the composite material used as plate and patch material were given in Table 1.

\begin{tabular}{cc} 
Table I. Mechanic properties of composite plate and patch [ 19$].$ \\
\hline \multicolumn{1}{c}{ Mechanic properties } & Values \\
\hline Elasticity modulus in fiber direction $\left(\mathrm{E}_{1}\right)(\mathrm{GPa})$ & 48 \\
Elasticity modulus in cross direction $\left(\mathrm{E}_{2}\right)(\mathrm{GPa})$ & 15.3 \\
Elasticity modulus in thickness direction $\left(\mathrm{E}_{3}\right)(\mathrm{GPa})$ & 15.3 \\
In-plane shear modulus $\left(\mathrm{G}_{12}\right)(\mathrm{GPa})$ & 5.1 \\
Out-plane shear modulus $\left(\mathrm{G}_{23}\right)(\mathrm{GPa})$ & 5.8 \\
Out-plane shear modulus $\left(\mathrm{G}_{23}\right)(\mathrm{GPa})$ & 5.1 \\
Poisson's ratio $\left(v_{12}\right)$ & 0.315 \\
Poisson's ratio $\left(v_{23}\right)$ & 0.332 \\
Poisson's ratio $\left(v_{13}\right)$ & 0.315 \\
Density $(p)\left(\mathrm{kg} / \mathrm{m}^{3}\right)$ & 2112 \\
\hline
\end{tabular}

Furthermore, three-different adhesives have been preferred in the patch repaired composite and the properties of these materials were presented in Table 2.

Table 2. Mechanic properties of adhesive [20,21,22].

\begin{tabular}{|c|c|c|c|}
\hline Adhesives & $\begin{array}{c}\text { Elasticity } \\
\text { modulus (E) } \\
(\mathrm{GPa})\end{array}$ & $\begin{array}{c}\text { Poisson's ratio } \\
\text { (v)(-) }\end{array}$ & $\begin{array}{c}\text { Density }(\rho) \\
\left(\mathbf{k g} / \mathrm{m}^{3}\right)\end{array}$ \\
\hline FM 73 [20] & 2.140 & 0.35 & 1150 \\
\hline EN II 343 [2I] & 1.000 & 0.40 & 1200 \\
\hline EA 9395 [22] & 4.102 & 0.30 & 1273 \\
\hline
\end{tabular}

The geometric model created for the circular hole of the adhesives was given in Figure 2 and the adhesive thicknesses are $1 \mathrm{~mm}, 0.5 \mathrm{~mm}$ and $0.25 \mathrm{~mm}$. Patches used in the repair of composite plates were two-layered and $\left[0^{\circ} / 45^{\circ}\right]$ alignment angles. Each layer with a thickness of $0.5 \mathrm{~mm}$ was modeled as circle (radius $30 \mathrm{~mm})$, square $\left(60 \times 60 \mathrm{~mm}^{2}\right)$ and hexagon (edge length $30 \mathrm{~mm}$ ). In addition, the patch edge sizes were also changed as 50,70 and $80 \mathrm{~mm}$ for each square patch.

The material properties of the striker model were given in Table 3 and the weight of the striker was set as $5 \mathrm{~kg}$. By taking the density values into consideration, their volumes were calculated and modeled in a way to provide the striker weight (Figure 3) while designing the striker geometries. Strike velocity was selected as 1,2 and $3 \mathrm{~m}$ /h. The boundary conditions of the composite material: four different boundary conditions were used, and these were fixed support on four sides of the plate, pin support on four sides, fixed support on two sides, free support on the other two sides, and finally pin support on two sides.

\begin{tabular}{cc} 
Table 3. Mechanic properties of striker & \\
\hline Mechanic properties & Values \\
\hline Elasticity modulus $(\mathrm{GPa})$ & 200 \\
Poisson's ratio & 0.3 \\
Density $(\rho)\left(\mathrm{kg} / \mathrm{m}^{3}\right)$ & 8107.62 \\
\hline
\end{tabular}

\subsection{Finite Element Model}

ANSYS LS-Dyna software; It is one of the package programs used in the solution of engineering problems with the computer aided finite element method and was preferred because it provides convenience and practicality

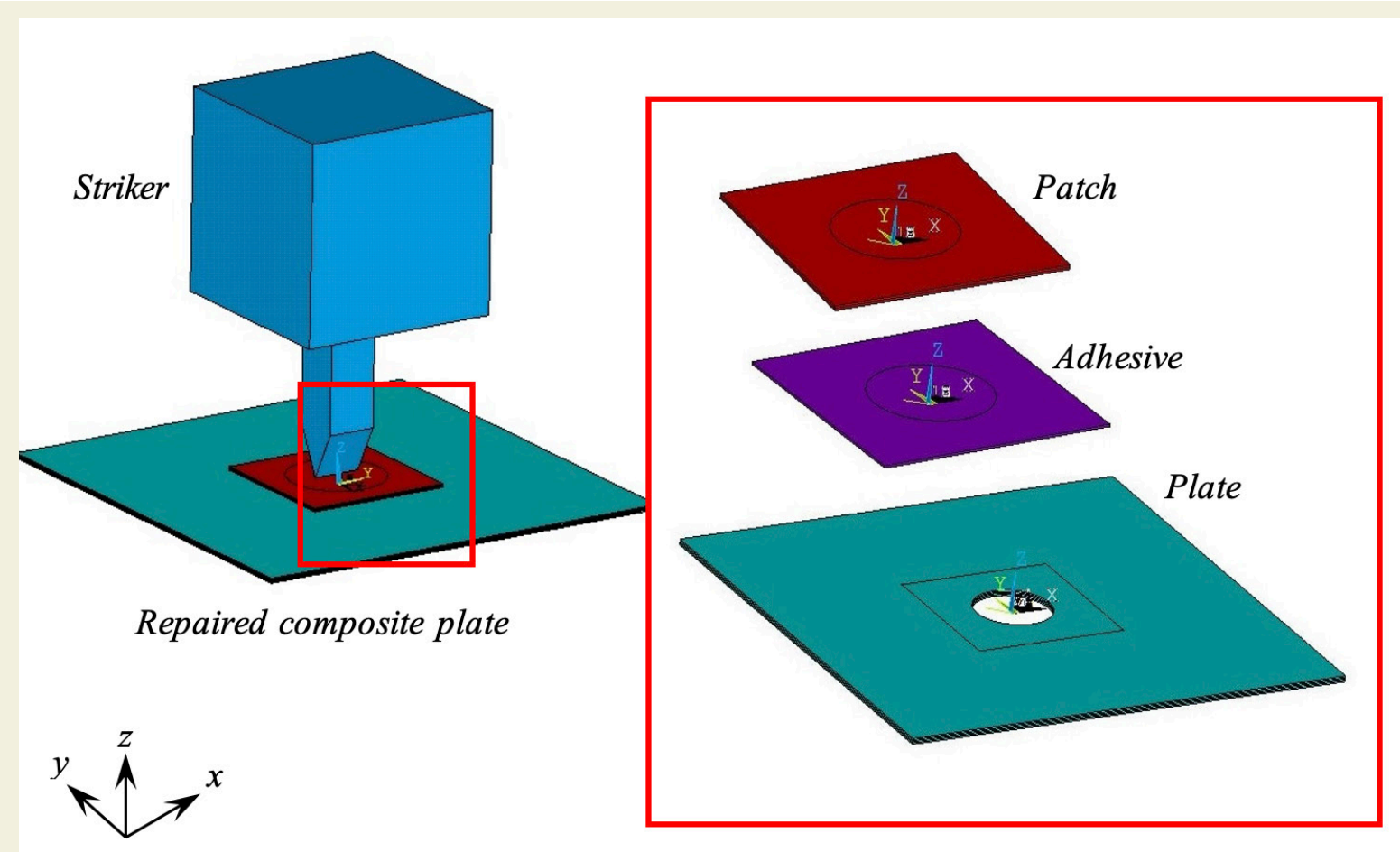

Figure 1. Model of repaired composite plate and striker 


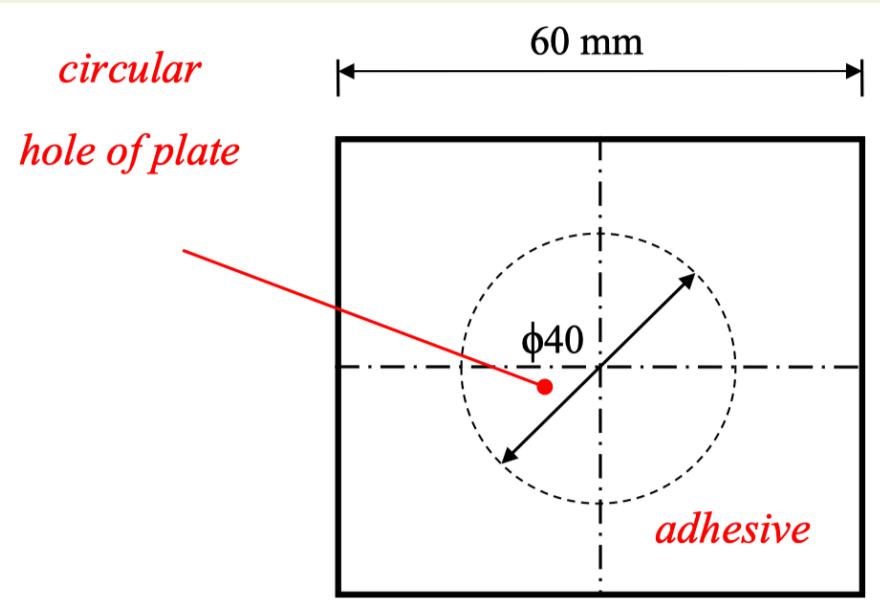

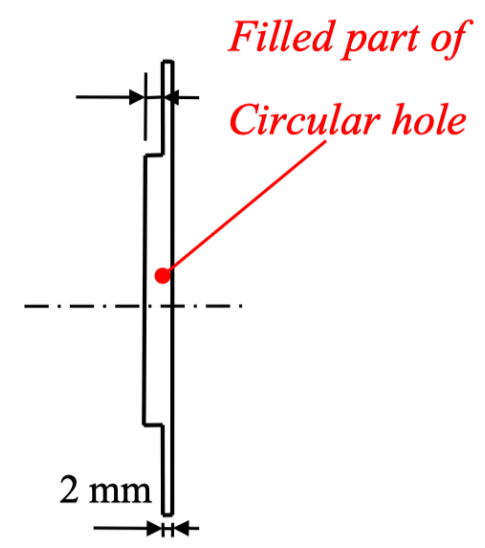

Thickness: $0.25,0.5$ and $1 \mathrm{~mm}$

Figure 2. The dimensions of adhesive model.

in solving problems. In the finite element model (FEM), the SOLID 164 element type is used for the striker and composite material. After defining and modeling the material properties of the striker and the plate, finite element division was performed at appropriate frequencies. In addition, surface to surface -Automatic (ASTS) option has been used to define the required contact properties between the striker and the plate. The initial velocity of the striker is $3 \mathrm{~m} / \mathrm{s}$, and the acceleration of gravity was modeled in contact with the plate in order to be in contact with the striker. The operational steps of ANSYS LS-Dyna software are shown in Figure 4.

The graph of the contact force node number depending on the change in the number of nodes is given in Figure 5. The problem for values between 9600 and 10400 nodes was solved in the graph. According to the results obtained, it was observed that the force change was constant for the number of 10280 nodes and thereafter. In the light of this information, the number of node for finite element model solutions was determined as 10280 . The finite ele-
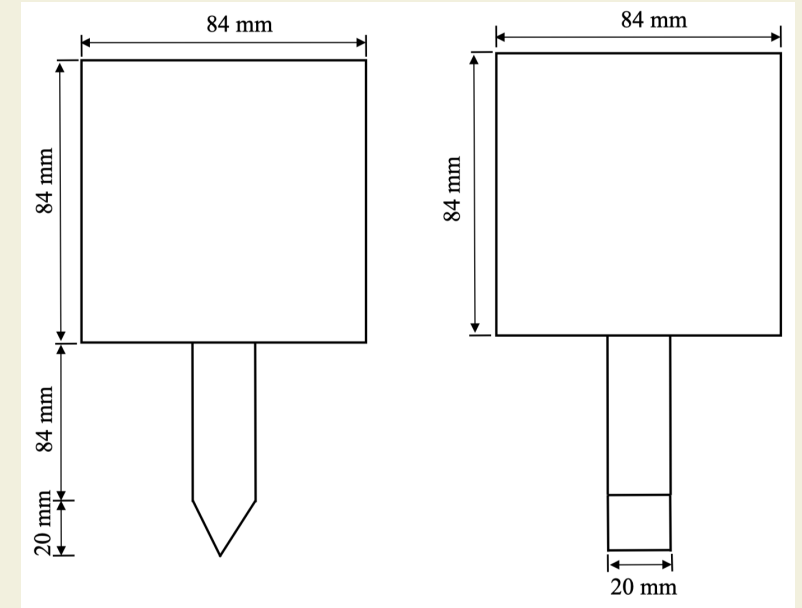

Figure 3. The striker model. ment, the striker model of four-sided fixed support patchrepaired plate and the finite element model of the contact with the plate are presented in Figure 6.

\section{Results and Discussion}

In order to verify the results of the study, the existing experimental study in the literature [23] was taken as reference and the results were numerically analyzed and compared under the same boundary conditions. In his study, Kara [23] investigated the dynamic behavior of E - glass / epoxy layered composites exposed to low velocity impact.

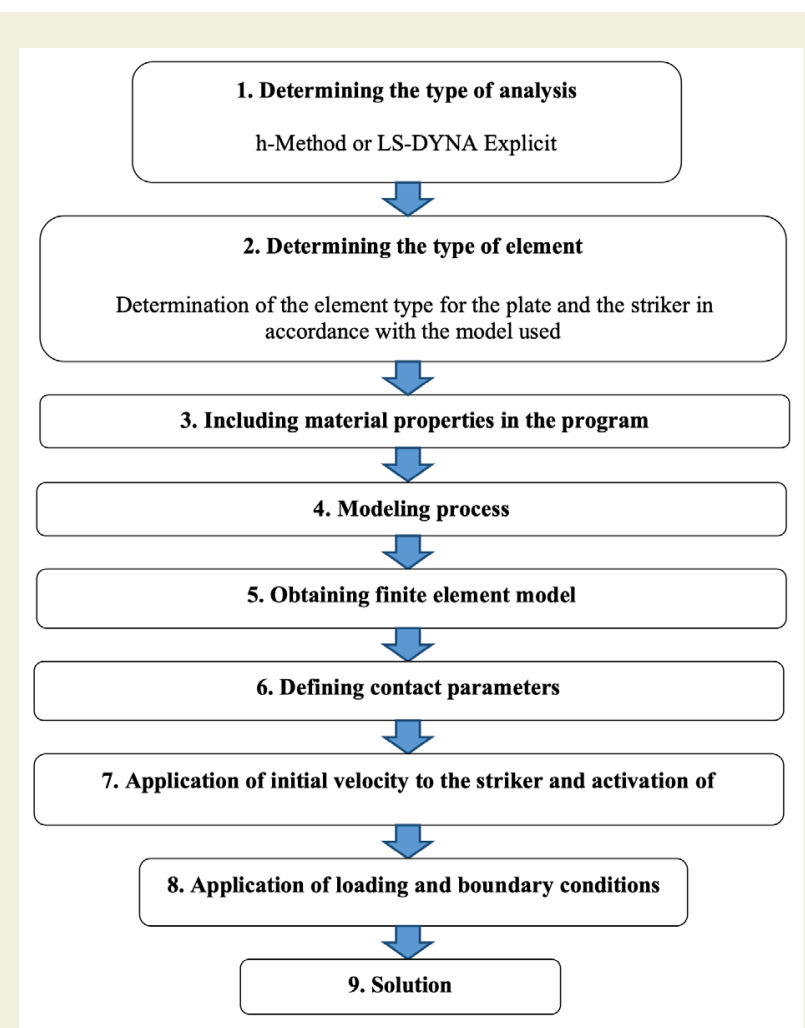

Figure 4. The operational steps of ANSYS LS-Dyna software. 


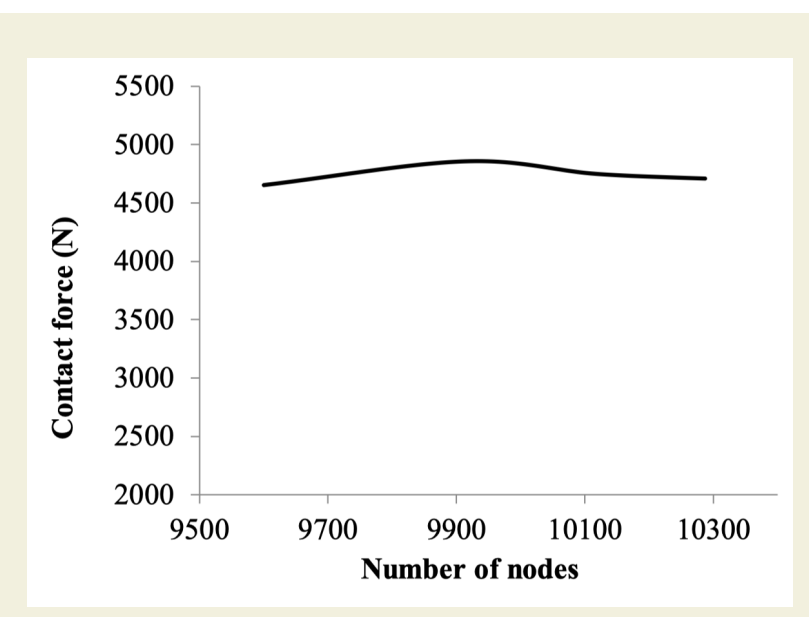

Figure 5. Variation of force with number of nodes.

E glass-epoxy composite plate were obtained by arranging unidirectional reinforced composite layers as $[0 \%-45 \%$ $\left.45^{\circ} / 0^{\circ} / 90^{\circ} / 0^{\circ} \%+45^{\circ} /-45^{\circ} / 0^{\circ}\right]$ s. Then, low-velocity impact tests were carried out with the impact test device on these plates. The striker used in impact tests weighs $30 \mathrm{~kg}$ and was diameter of $24 \mathrm{~mm}$. Initial velocity of the striker with a hemispherical tip is $3 \mathrm{~m} / \mathrm{s}$. Composite plates of 180 $\times 50 \mathrm{~mm}^{2}$ were designed so as to have two free and two fixed-support edges. The sample thickness is $7 \mathrm{~mm}$ and the striker tip positioned so as to hit the center of the plate. In the light of the results obtained from the experiments, he was evaluated the impact strength of the composite plates by drawing a contact force-time diagram. While model- ing the experimental study in the literature with FEM, SHELL 163 for composite material and SOLID 164 element type for the striker were used. The mechanical properties of the composite plate and striker model are given in Table 4. In addition, the geometric features of the striker model and the FEM model of the contact with the plate are presented in Figure 7.

\begin{tabular}{cccc}
\hline Table 4. Mechanic properties of composite plate [23] & \\
\hline Mechanic Properties & $\begin{array}{c}\text { Symbol } \\
\text { (Unit) }\end{array}$ & Plate & $\begin{array}{c}\text { Stri- } \\
\text { ker }\end{array}$ \\
\hline Density & $p\left(\mathrm{~kg} / \mathrm{m}^{3}\right)$ & 1840 & 7860 \\
Elasticity modulus in fiber direction & $\mathrm{E}_{\mathrm{L}}(\mathrm{GPa})$ & 42 & 200 \\
Elasticity modulus in cross direction & $\mathrm{E}_{\mathrm{T}}(\mathrm{GPa})$ & 9.5 & 200 \\
In-plane shear modulus & $\mathrm{G}_{\mathrm{LT}}(\mathrm{GPa})$ & 3.5 & 76.92 \\
Maximum Poisson's ratio & $v_{\mathrm{LT}}(-)$ & 0.34 & 0.3 \\
\hline
\end{tabular}

In this study, which was carried out in parallel with the experimental study, it was observed that the experimental and numerical results were compatible with each other (Figure 8). In order to examine the effect of the striker velocity on the impact behavior, the striker model, whose geometric details are given in Figure 3, is used. The striker weighs $5 \mathrm{~kg}$ and its initial velocity is 1,2 and $3 \mathrm{~m} / \mathrm{s}$, respectively. It is modeled to contact with the plate centers (Figure 6c).

When the contact force-time diagram (Figure 9) is exam- a)
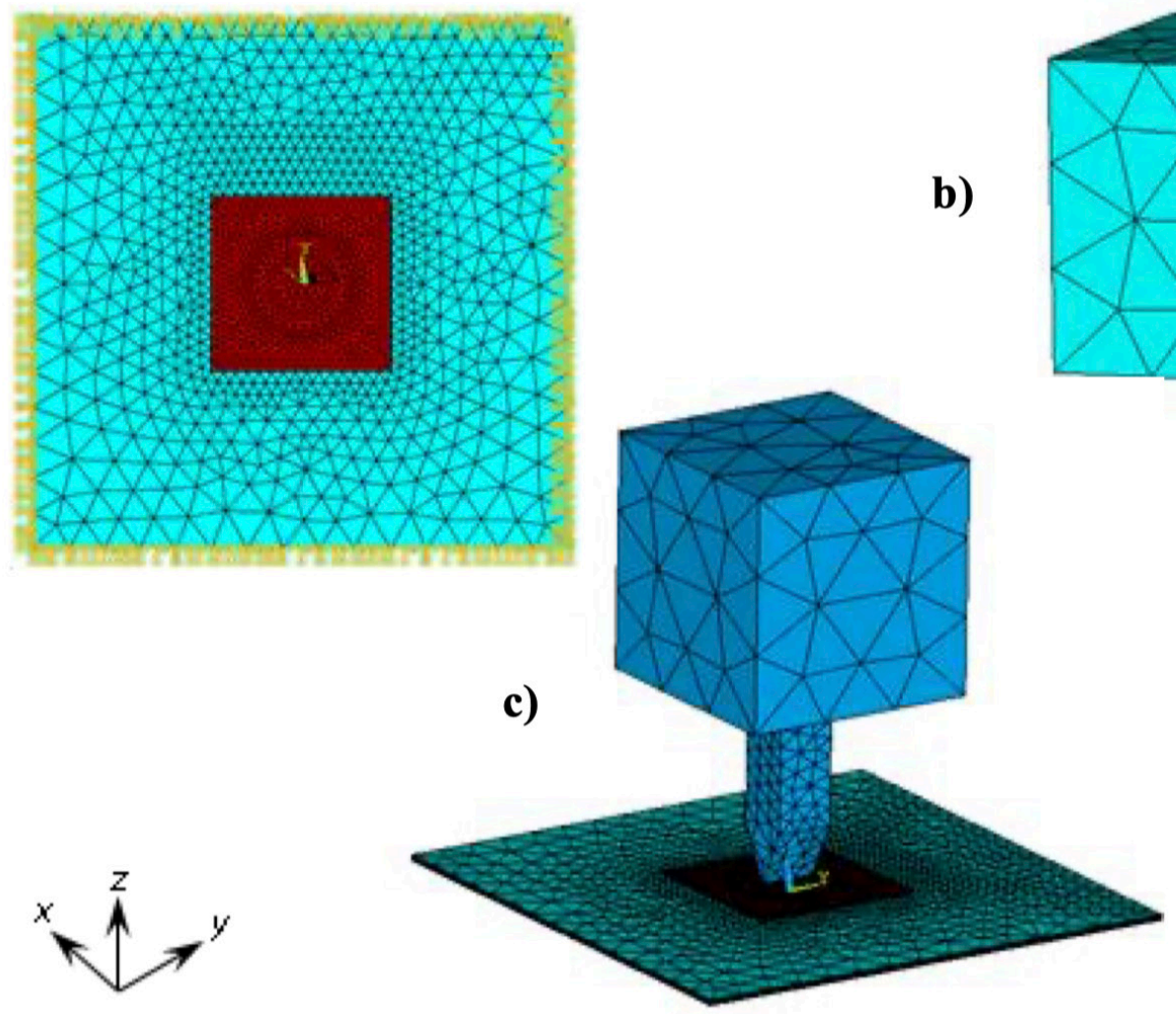

b)

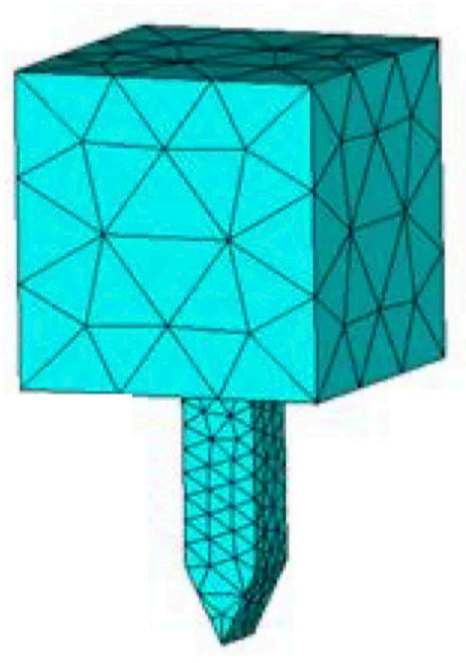

Figure 6. a) Finite element model of four-sided fixed support plate, b) Finite element model of the striker, c) Finite element model of the problem 


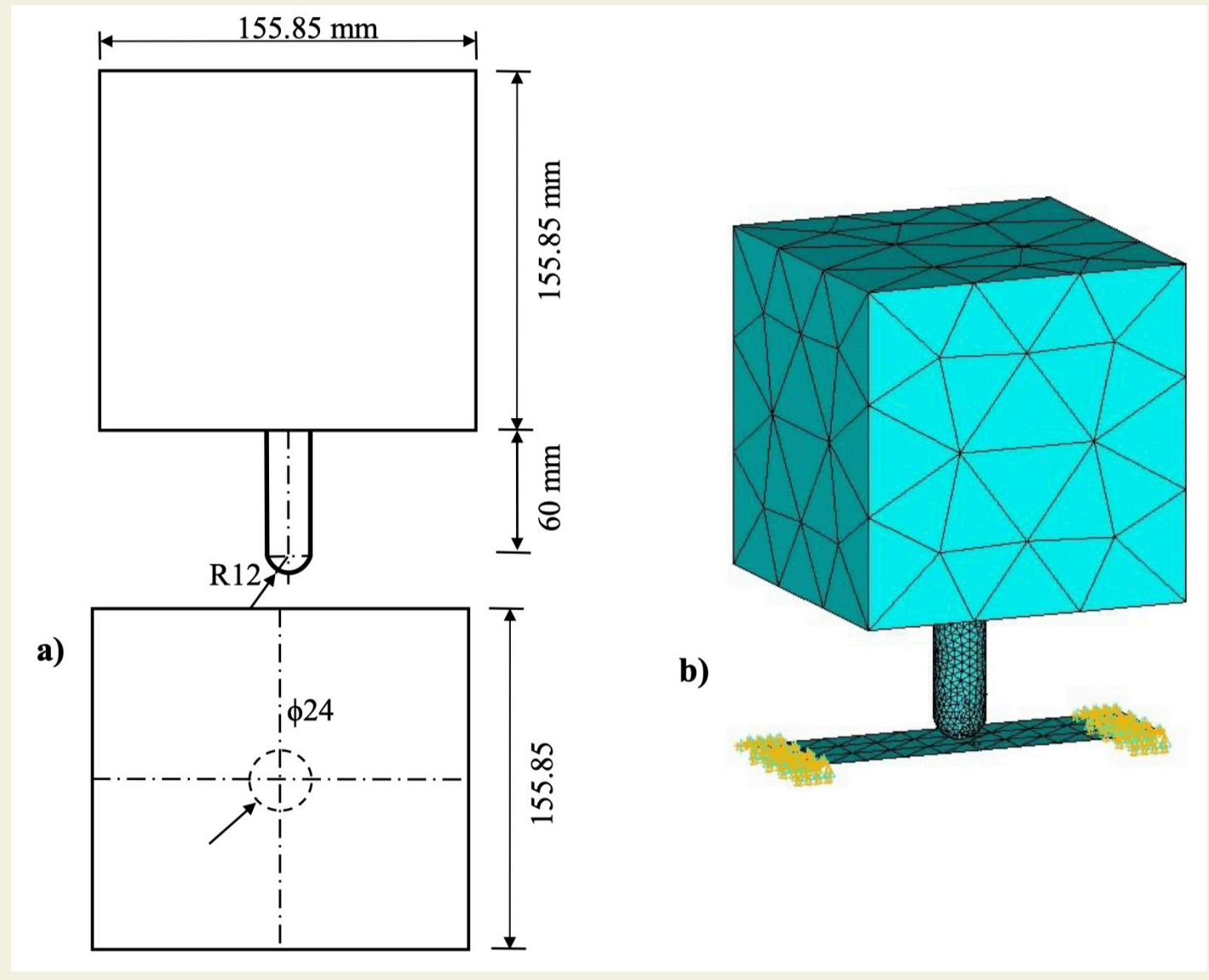

Figure 7. a) The dimensions of striker, b) Finite element of the problem [23]

ined, depending on the impact velocity change, it was observed that the contact force increased in accordance with the increase in impact velocities [12]. It was evaluated that the initial steep increase in load was due to the elastic behavior of the samples and that the slope increased with the velocity. its rising diagram is followed by a decrease in loading $(3 \mathrm{~m} / \mathrm{s})$ corresponding to the initial major deformation. In practical application, minor failures (intralaminar delamination and matrix cracking) caused by impact begin to spread beyond the contact point [12]. The contact force measured with the recoil of the striker contin-

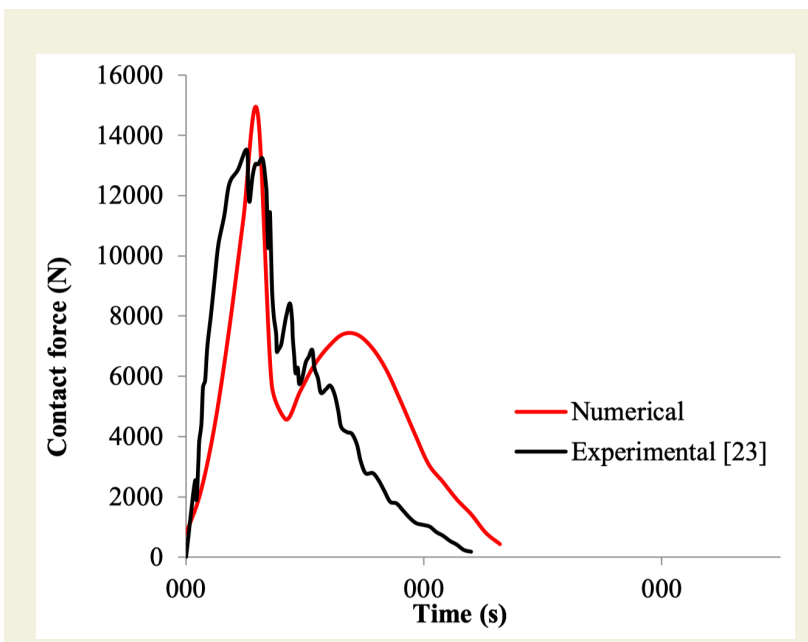

Figure 8. Comparison of the results with the literature ues, gradually decreasing. In impact analysis, the impact energy (kinetic energy) of the striker is transferred to the plate after contact with it. At the time of impact, part of this energy is the energy absorbed in the form of elastic deformation (elastic energy) by the plate [24]. Excess energy is dissipated through various failure mechanisms such as fiber breakage, delamination, fiber-matrix debonding, and matrix cracking. Therefore, the energy absorbed by the sample is an indicator of the extent of the failure [25]. When the impact energy of the plate is examined (Table 5) depending on the change of the striker velocity, its kinetic energy is expected to naturally increase with the in-

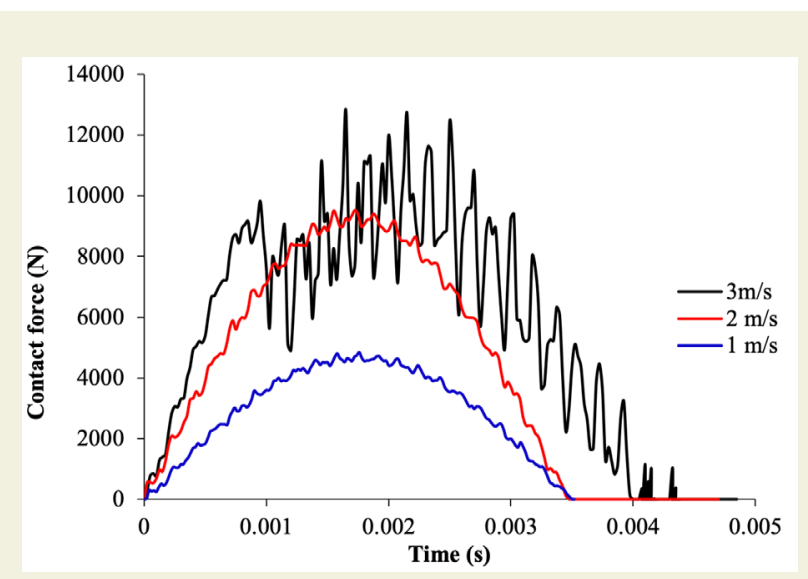

Figure 9. Variation of contact force with time for different impact velocity. 
Table 5. Total energy of striker depending on the impact velocity.

\begin{tabular}{|c|c|}
\hline Striker velocity $(\mathrm{m} / \mathrm{s})$ & Impact energy (j) \\
\hline 1 & 2.57 \\
\hline 2 & 10.05 \\
\hline 3 & 22.62 \\
\hline
\end{tabular}

crease of the impact velocity.

Therefore, it was determined that the total energy increased parallel to the impact velocity [23]. When the maximum displacement-time diagram in the direction parallel to the direction of impact (z-axis) of the plate depending on the impact velocity is examined, it has been observed that the displacement due to the impact on the plate increased with the velocity increase [23] (Figure 10).

The maximum displacement in the $\mathrm{z}$ direction for $1 \mathrm{~m} / \mathrm{s}$ was approximately $1.1 \mathrm{~mm}, 2.2 \mathrm{~mm}$ for $2 \mathrm{~m} / \mathrm{s}$, and $2.9 \mathrm{~mm}$ for $3 \mathrm{~m} / \mathrm{s}$. Depending on the change of hole diameter $(\phi 30,35,40,45$ and $50 \mathrm{~mm})$, in the layered composite plate with a circular hole in the middle, the contact force time diagram at 0.001 s was drawn along with the contact of the striker with the plate (Figure 11). Sudden decreases in contact force were seen, especially at diameters over $40 \mathrm{~mm}$. In addition, when the graph was examined, it was observed that the reaction force decreased due to

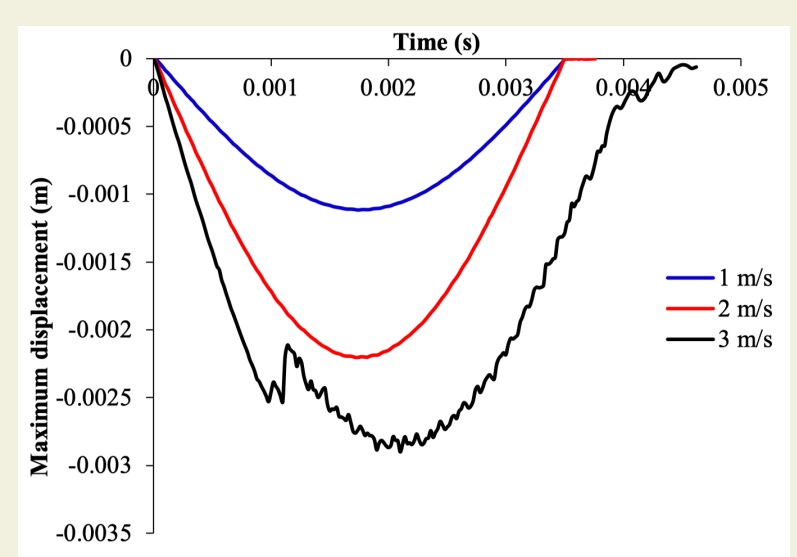

Figure 10. Variation of maximum displacement with time for different impact velocity.

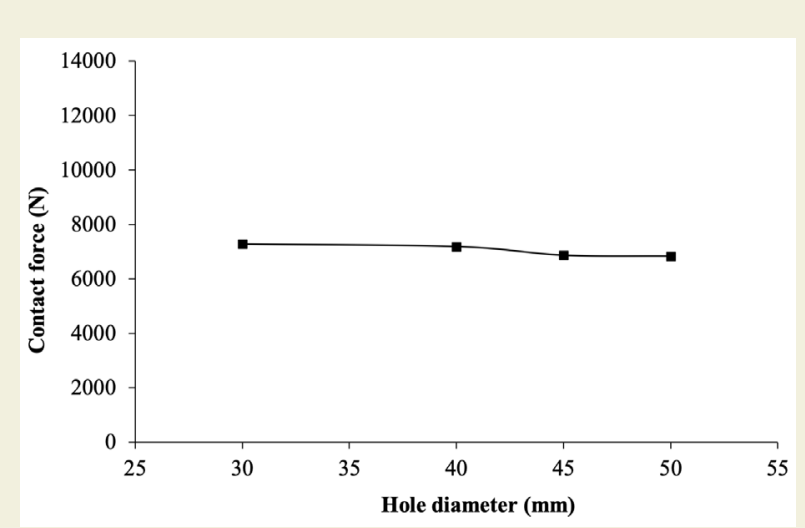

Figure 11. Variation of contact force with hole diameter. the increase of hole diameter. This is because the increase in hole size reduces the overlapping area, resulting in less load transfer across the patch [4].

In Figure 12, the contact force time diagram was given depending on the change of hole type (circle, square, hexagon) in the center of the composite plate. The surface areas of these holes are $1256 \mathrm{~mm}^{2}, 1600 \mathrm{~mm}^{2}$ and $1039 \mathrm{~mm}^{2}$ for circle, square and hexagonal holes, respectively. Therefore, the same situation with the change of hole diameter is also seen here. Because of this, as the hole cross-sectional area decreased, the contact surface of the patched plate increased and accordingly the load carrying capacity increased. Three different adhesive materials were used in the patch repair of the plate with a circular hole in the middle.

Figure 13 shows the effects of the adhesive materials on the force time diagram. The elasticity modules of the adhesives used in descending order; EA9395> FM73> EN11343. When the graph is examined, it has been observed that the contact forces related to this have increased [26].

The adhesive material used for patch reinforcement is FM 73, and a solution was made for different thicknesses $(0.25,0.5$ and $1 \mathrm{~mm})$ of this adhesive. According to the results, just as the thickness of the adhesive increases, the

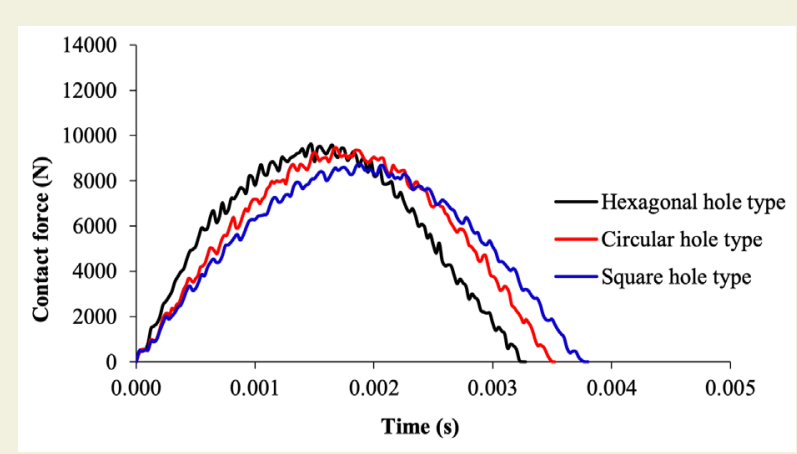

Figure 12. Variation of contact force with time for different hole shape

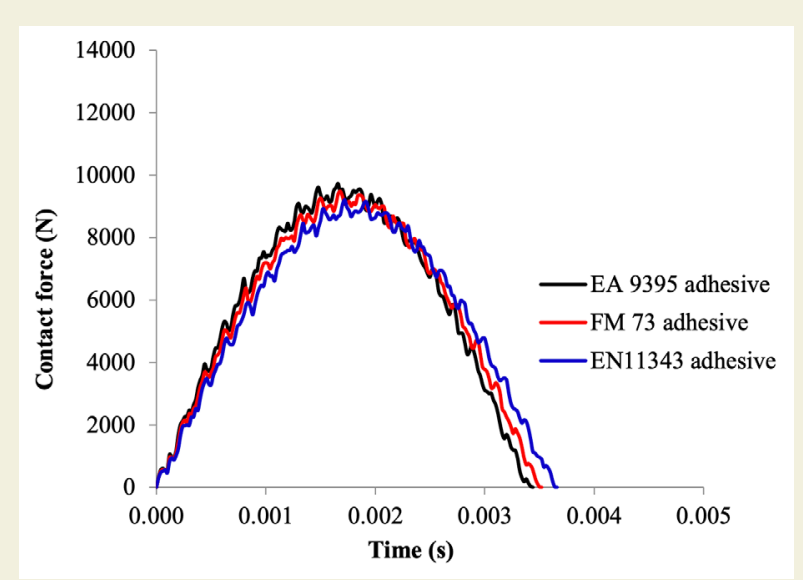

Figure 13. Variation of contact force with time for different adhesive material 
reaction force also increases (Figure 14). Cheng et al. [1] repaired carbon fiber composites with adhesives of different thicknesses and passed them through low-velocity impact tests. They determined that the maximum impact force increased parallel to the thickness of the adhesive. Composite plates with a circular hole in the center were repaired by using square patches of different sizes $(50 \times 50$, $60 \times 60,70 \times 70$ and $80 \times 80 \mathrm{~mm}^{2}$ ). When the effect of patch size on contact force was examined, it was observed that the contact force decreased as the patch size increased (Figure 15).

Tie et al. [8] used circular patches of different radius in order to examine the effect of patch size on the contact force and determined that the contact force decreased as the radius diameter increased. In order to examine the effect of patch type on impact behavior, solutions were made by using square, circle and hexagonal patches (Figure 16). When the graph was examined, the results of the circle and square patch types were similar, and higher contact force was obtained in the hexagonal patch repaired plates. However, when the force oscillation amplitude in the graphs was evaluated, it was observed that the minimum impact force change occurred in the hexagonal patch and the maximum force oscillation occurred in the square patch. This indicates that the hexagonal patch repaired structure absorbs less impact energy than the others.

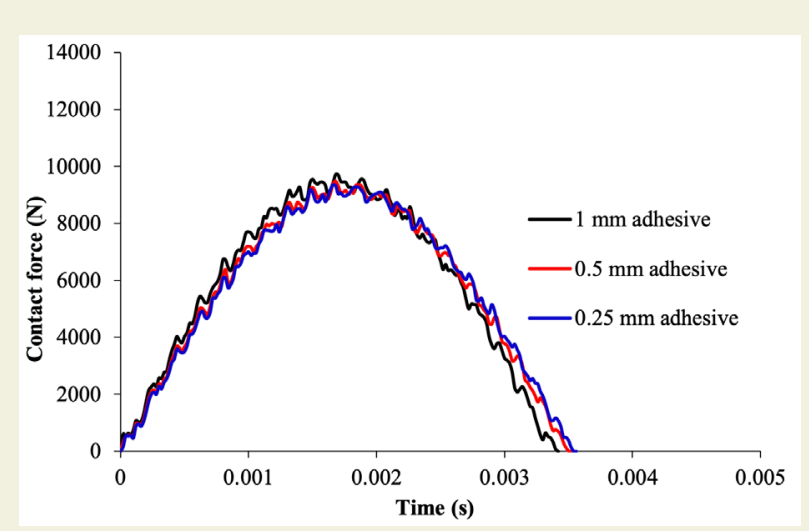

Figure 14. Variation of contact force with time for different adhesive thickness.

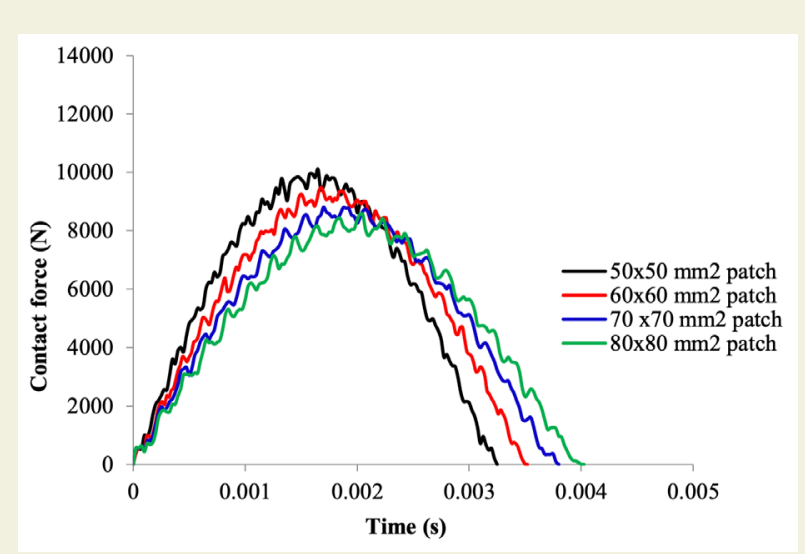

Figure 15. Variation of contact force with time for different patch size.
Low absorption energy determines the amount of energy absorbed by the plate that can cause damage, and this amount was aimed to be at the minimum level. Therefore, it is understood that the repair performance of the hexagonal patch is better than the other patch types. [8].

The effect of four different support conditions on the impact behavior was evaluated: four-sided fixed support, four-sided pin support, two-sided fixed support - two-sided free, two-sided pin support and two-sided free (Figure 17). According to the results, it was determined that the contact force values of four-sided pin support and four-sided fixed support were close to each other. The same situation is true for two-sided fixed -two-sided free support and two-sided fixed- two-sided free support. In addition to this, \% 9.86 more contact force was obtained in 4 side supports (pin or fixed) compared to 2 sides supports. Figure 18-20 shows the graphs of the maximum tensile and compression stresses in the striker direction (z-axis) for the striker velocity of 1,2 and $3 \mathrm{~m} / \mathrm{s}$, respectively. As a result of the contact of the striker with the plate, compression stresses were occurring on the patch contact surface and maximum tensile stresses were occur on the opposite surface. When the stress bar is examined, it has been determined that the tensile-compression stresses taking place in the striker plates increase in accordance with the striker impact velocity and energy.

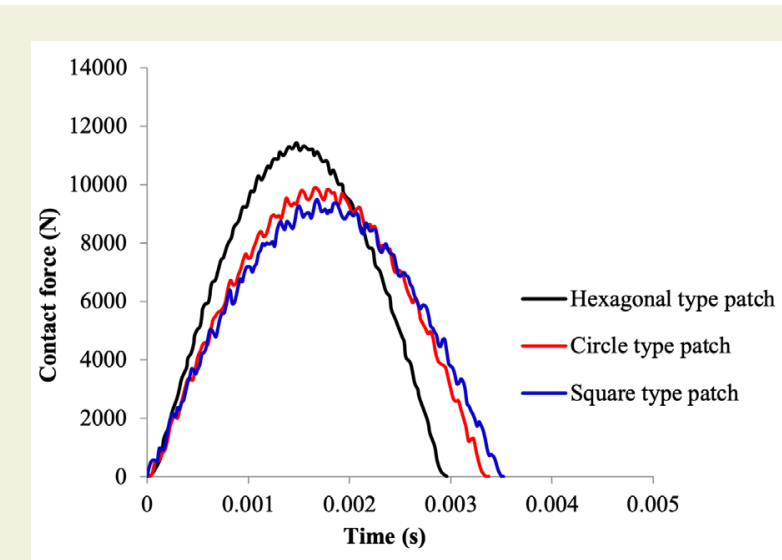

Figure 16. Variation of contact force with time for different patch size.

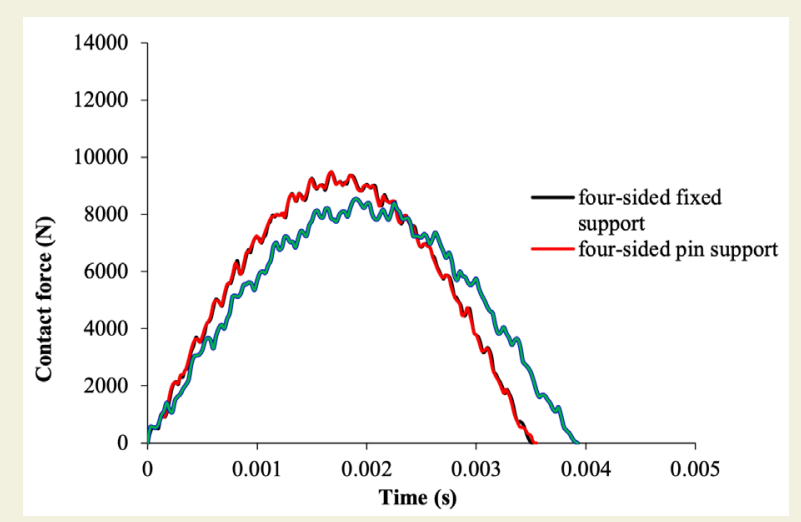

Figure 17. Variation of contact force with time for different support type. 

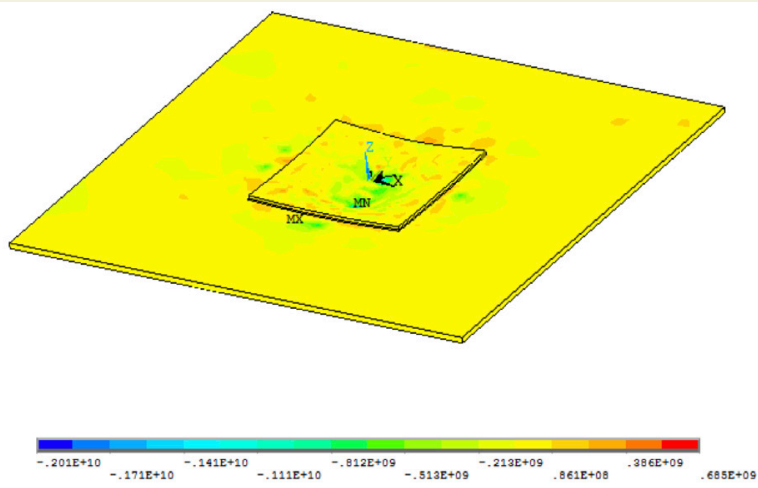

Figure 18. Stress distribution at the direction of striker.
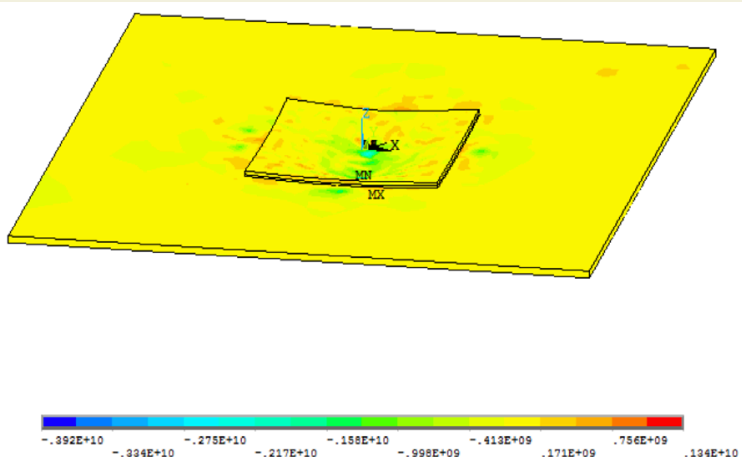

Figure 19. Stress distribution at the direction of striker.
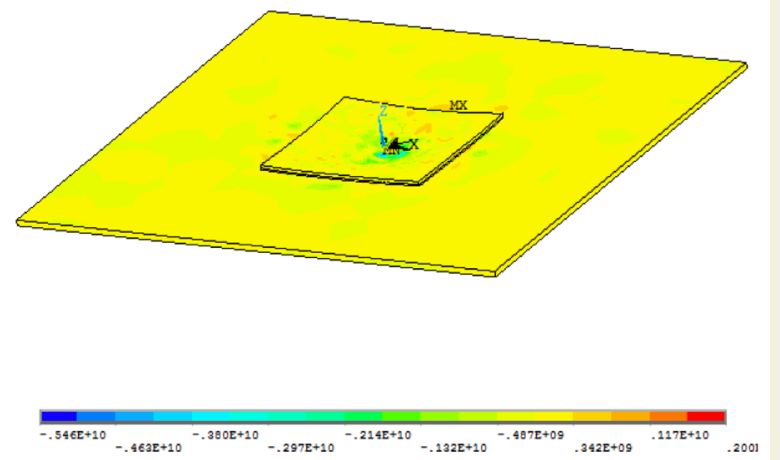

Figure 20. Stress distribution at the direction of striker.

\section{Conclusion}

In this study, the impact behavior of patch-repaired E-glass / epoxy laminates under low-velocity impact was solved using a numerical approach. Patch-repaired samples were obtained on the plates where a hole was accepted as failure. Numerically low velocity impact tests have been successfully applied to examine the effect of various patches and hole design parameters like shape and size on the repair performance of variables such as striker speed, adhesive material, and adhesive thickness. In order to show the accuracy of the numerical study, it was solved under the same boundary conditions with the existing experimental study and it was observed that the results obtained were compatible with each other. The results obtained can be briefly summarized as follows;

- When evaluating the impact of the striker velocity on the contact force, it was determined that the higher the striker velocity, the more load was transferred to the plate. In addition, it was observed that the total energy and the amount of displacement increased due to the impact on the plate in the direction of the striker.

- In order to recover damaged laminates, circular holes of $40 \mathrm{~mm}$ diameter are modeled in the center of the plate. Comparing the repair performance of plates which were reinforced with square patches of different sizes, the increase of the patch surface enhanced the contact with the plate and decreased the contact force.

- When the effect of adhesives having different thicknesses and material properties on impact strength is examined, it has been observed that adhesives with greater thickness and higher elasticity module have positive contributions to the impact behavior.

- When the effect of hole diameters of patch-repaired plates on the impact behavior was investigated, it was assessed that with the reduction of the hole diameter, plates with higher impact strength were obtained and more load transfer was provided by the patches.

- Similar results are true for different hole geometries (square, circle, and hexagon) with the same radius and edge lengths. It has been observed that the hexagonal hole which has the smallest surface showed a better performance. When the effect of different patch geometries (square, circle and hexagon) is evaluated, it is seen that hexagonal patches come to the fore.

- When the repair performance parameters are studied, it is revealed that the patch size and shape is an important design element. Designers may prefer the use of hexagonal patches over patch-repaired composites with as large a contact surface as possible. Adhesive thickness and mechanical properties do not have as much effect on the impact behavior as other parameters.

\section{Rererences}

[1] Cheng, X., Zhang, J., Bao, J., Zeng, B., Cheng, Y., Hu, R. (2018). Low-velocity impact performance and effect factor analysis of scarf-repaired composite laminates. International Journal of Impact Engineering, vol.111, pp. 85-93.

[2] Ivañez, I., Garcia-Castillo, S. K., Sanchez-Saez, S., Barbero, E. (2019). Analysis of the impact location on damage tolerance of bonded-repaired composite laminates. Polymer Testing, vol.78, 106000.

[3] Tie, Y., Hou, Y., Li, C., Meng, L., Sapanathan, T., Rachik, M. (2020). Optimization for maximizing the impact-resistance of patch repaired CFRP laminates using a surrogate-based model. International Journal of Mechanical Sciences, vol.172, 105407.

[4] Kashfuddoja, M., Ramji, M. (2014). Design of optimum 
patch shape and size for bonded repair on damaged Carbon fiber reinforced polymer panels. Materials and Design (1980-2015), vol.54, pp. 174-183.

[5] Kara, M., Uyaner, M., Avci, A. (2015). Repairing impact damaged fiber reinforced composite pipes by external wrapping with composite patches. Composite Structures, vol.123, pp. 1-8.

[6] Andrew, J. J., Arumugam, V., Saravanakumar, K., Dhakal, H. N., Santulli, C. (2015). Compression after impact strength of repaired GFRP composite laminates under repeated impact loading. Composite structures, vol.133, pp. 911-920.

[7] Coelho, S. R. M., Reis, P. N. B., Ferreira, J. A. M., Pereira, A. M. (2017). Effects of external patch configuration on repaired composite laminates subjected to multi-impacts. Composite Structures, vol.168, pp. 259-265.

[8] Tie, Y., Hou, Y., Li, C., Zhou, X., Sapanathan, T., Rachik, M. (2018). An insight into the low-velocity impact behavior of patch-repaired CFRP laminates using numerical and experimental approaches. Composite Structures, vol.190, pp.179-188.

[9] Choi, I. H. (2016). Geometrically nonlinear transient analysis of composite laminated plate and shells subjected to low-velocity impact. Composite Structures, vol.142, pp. 7-14.

[10] Hu, Y., Liu, W., Shi, Y. (2019). Low-velocity impact damage research on CFRPs with Kevlar-fiber toughening. Composite Structures, vol.216, pp.127-141.

[11] Zhang, Y., Sun, L., Li, L., Wang, T., Shen, L. (2019). Experimental and numerical investigations on low-velocity impact response of high strength steel/composite hybrid plate. International Journal of Impact Engineering, vol.123, pp.1-13.

[12] Liu, H., Falzon, B. G., Tan, W. (2018). Experimental and numerical studies on the impact response of damage-tolerant hybrid unidirectional/woven carbon-fiber reinforced composite laminates. Composites Part B: Engineering, vol.136, pp.101-118.

[13] Liu, P. F., Liao, B. B., Jia, L. Y., Peng, X. Q. (2016). Finite element analysis of dynamic progressive failure of carbon fiber composite laminates under low velocity impact. Composite Structures, vol.149, pp. 408-422.

[14] Zhang, C., Duodu, E. A., Gu, J. (2017). Finite element modeling of damage development in cross-ply composite laminates subjected to low velocity impact. Composite Structures, vol.173, pp.219-227.

[15] Bunea, M., Circiumaru, A., Buciumeanu, M., Birsan, I. G., Silva, F. S. (2019). Low velocity impact response of fabric reinforced hybrid composites with stratified filled epoxy matrix. Composites Science and Technology, vol.169, pp.242-248.

[16] Ismail, K. I., Sultan, M. T. H., Shah, A. U. M., Jawaid, M., Safri, S. N. A. (2019). Low velocity impact and compression after impact properties of hybrid bio-composites modified with multi-walled carbon nanotubes. Composites Part B: Engineering. vol.163, pp.455-463.

[17] Menna, C., Asprone, D., Caprino, G., Lopresto, V., Prota, A. (2011). Numerical simulation of impact tests on GFRP composite laminates, International Journal of Impact Engineering. vol.38, pp.677-685.
[18] Liu, J., He, W., Xie, D., Tao, B. (2017). The effect of impactor shape on the low-velocity impact behavior of hybrid corrugated core sandwich structures. Composites Part B: Engineering. vol. 111, pp.315-331.

[19] Naik, N. K., Sekher, Y. C., Meduri, S. (2000). Damage in woven-fabric composites subjected to low-velocity impact. Composites Science and Technology. vol. 60, pp.731-744.

[20] Park, H., Kim, H. (2010). Damage resistance of single lap adhesive composite joints by transverse ice impact. International Journal of Impact Engineering. vol. 37, pp. 177-184.

[21] Challita, G., Othman, R. (2010). Finite-element analysis of SHPB tests on double-lap adhesive joints. International Journal of Adhesion and Adhesives. vol.30, pp.236-244.

[22] Chiu, W. K., Zhou, Z., Wang, J., Baker A. (2012). Battle damage repair of a helicopter composite main rotor blade. Composites Part B: Engineering, vol.43 pp. 739-753.

[23] Kara, M. (2006). Dynamic response of laminated composites subjected to low velocity impact. PhD Thesis, Selçuk University Graduate School of Natural and Applied Sciences.

[24] Garcia-Moreno, I., Caminero, M. A., Rodríguez, G. P., Lopez-Cela, J. J. (2019) Effect of thermal ageing on the impact damage resistance and tolerance of carbon-fiber-reinforced epoxy laminates. Polymers, vol. (11) pp. 160.

[25] Selver, E., Potluri, P., Hogg, P., Soutis, C. (2016). Impact damage tolerance of thermoset composites reinforced with hybrid commingled yarns. Composites Part B: Engineering. vol.91, pp. 522-538.

[26] Barzegar, M., Moallem, M. D., Mokhtari, M. (2020). Progressive damage analysis of an adhesively bonded composite T-joint under bending, considering micro-scale effects of fiber volume fraction of adherents. Composite Structures. 113374. 